\title{
Altered activity patterns of transcription factors induced by endoplasmic reticulum stress
}

\author{
Sheena Jiang ${ }^{1}$, Eric Zhang ${ }^{2}$, Rachel Zhang ${ }^{2}$ and Xianqiang Li $^{1^{*}}$
}

\begin{abstract}
Background: The endoplasmic-reticulum (ER) responds to the burden of unfolded proteins in its lumen by activating intracellular signal transduction pathways, also known as the unfolded protein response (UPR). Many signal transduction events and transcription factors have been demonstrated to be associated with ER stress. The process in which ER stress affects or interacts with other pathways is still a progressing topic that is not completely understood. Identifying new transcription factors associated with ER stress pathways provides a platform to comprehensively characterize mechanism and functionality of ER.
\end{abstract}

Methods: We utilized a transcription factor (TF) activation plate array to profile the TF activities which were affected by ER stress induced by pharmacological agents, thapsigargin (TG) and tunicamycin (TM) at $1 \mathrm{~h}, 4 \mathrm{~h}, 8 \mathrm{~h}$ and $16 \mathrm{~h}$ respectively, in MiaPACA2 cells. The altered activity patterns were analyzed and validated using gel shift assays and cellbased luciferase reporter assay.

Results: The study has not only confirmed previous findings, which the TFs including ATF4, ATF6, XBP, NFkB, CHOP and AP1, were activated by ER stress, but also found four newly discovered TFs, NFAT, TCF/LEF were activated, and PXR was repressed in response of ER stress. Different patterns of TF activities in MiaPaCa2 were demonstrated upon TM or TG treatment in the time course experiments. The altered activities of TFs were confirmed using gel shift assays and luciferase reporter vectors.

Conclusion: This study utilized a TF activation array technology to identify four new TFs, HIF, NFAT, TCF/LEF and PXR that were changed in their activity as a result of ER stress induced by TG and TM. The TF activity patterns were demonstrated to be diverse in response to the duration of TG or TM treatment. These new findings will facilitate further unveiling the complex mechanisms of the ER stress process and associated diseases.

Keywords: ER stress, UPR, TF, Plate array, Activation and Signal pathways

\section{Background}

ER plays an important role in many biological functions such as folding and assembling the membrane and secreted proteins in eukaryotic cells [1]. Production process of these proteins in the lumen of the ER is believed to be led by the coordination between the extracellular and intracellular signals [2]. It has been previously reported [2-4] that, an imbalance between the protein-folding load and the capacity of the ER could happen due to either increase of proteinfolding demand or disruption of protein-folding reactions,

\footnotetext{
* Correspondence: jasonli@signosisinc.com

'Signosis Inc., 1700 Wyatt Drive, Suite \#10-12, Santa Clara, CA 95054, USA

Full list of author information is available at the end of the article
}

which will generate ER stress, and subsequently lead to accumulation of unfolded or misfolded proteins in the ER lumen. ER stress simultaneously activates Unfolded Protein Response (UPR) to reduce protein synthesis, degrade misfolded proteins, and produce molecular chaperones. The growing evidence suggests that ER stress (UPR) is an intricate molecular process, interacting with oxidative stress [5], $\mathrm{Ca}^{2+}$ signal response [6], and the inflammatory response and other signal pathways. In addition, ER stress is associated with a variety of diseases caused by the accumulation of aggregated proteins such as neurodegenerative diseases and diabetes [7]. 
It is well-known that in mammalian cells, the ER stress activates three distinct ER-localized transmembrane proteins, inositol-requiring enzyme 1 (IRE1), pancreatic ER kinase (PERK), and activating transcription factor 6 (ATF6) $[8,6]$. The timing and duration of activation of these three proteins may be different from the previous speculation of parallel responses [9]. For examples, the activation of PERK could inhibit the global protein translation through phosphorylation of eIF $2 \alpha$, and a translational increase in the transcription factor ATF4 would promote UPR-specific gene expression [10, 11], and IRE1 would lead to the generation of a more potent form of XBP1 mRNA splicing version [12]. Furthermore, ATF6, an ER membrane transcription factor [13], undergoes proteolysis to release its cytoplasmic transactivation domain to become active [9]. Therefore, PERK, IRE1, and ATF6 are ultimately responsible for the activation of a set of transcription factors through a complicated and nonparallel process.

Cells respond to ER stress by inducing gene expression. Consequently, a signal transduced from the ER to the nucleus is required to activate transcription in response to the ER Stress. Activated TFs as the endpoints of the signal transduction pathway directly regulates the final gene expression in the nucleus. Therefore, TF activation is a measure of the effectiveness of ER stress in activating the three proteins mentioned above in the cells. A number of transcription factors have been found to take part in ER stress response, such as ATF6 [13], XBP1 [12], ATF4 [9], NFkB [14], AP1 [14], SREBP and CHOP (CEBP homology) [15]. The activation of these TFs is believed to be associated with ER stress but through different mechanisms. The intrinsic ribonuclease activity of IRE1 also results in production and activation of XBP-1, inducing expression of genes involved in restoring protein folding or degrading unfolded proteins [12]. ATF4 is translationally up-regulated by eIF2amediated translational attenuation and PERK/eIF2 $\alpha \sim \mathrm{P} /$ ATF4 pathway is required not only for translational control, but also for activation of ATF6 [9] and CHOP and their target genes. Oligomerized Ire1 binds to TRAF2, TNF receptor associated factors, that activate NF- $\mathrm{B}$ and c-Jun (AP-1), leading to expression of a set of genesassociated with host defense or alarm [14]. In addition, the different transcription factors may display different response time patterns during ER stress process and variable pathways.

Pharmacological agents are commonly used to treat cells to elevate unfolded proteins in most studies of ER stress, including dithiothreitol (DTT), which disrupts or prevents protein disulfide bonding; thapsigargin (TG), an inhibitor of the ER Ca2 dependent ATPase; or tunicamycin (TM), an inhibitor of protein glycosylation of newly synthesized proteins [16]. However, the concentration and duration of treatment vary from system to system. Typically only a few hours are sufficient to induce ER stress while a longer exposure often lead ER stress-mediated cell to death. Previous studies have indicated that three ER transmembrane components, IRE1, PERK and ATF6, displayed distinct sensitivities toward different forms of ER stress induced by these three agents, but it is not clear how ER stress is affected in downstream pathways and transcriptional regulation.

In this study, we employed a TF activation profiling array to systematically monitor ER stress-induced TF activity patterns with $1 \mathrm{~h}, 4 \mathrm{~h}, 8 \mathrm{~h}$ and $16 \mathrm{~h}$ of TM and TG treatment in pancreatic tumor cell $\mathrm{MiaPaCa} 2$, since this cell line has demonstrated a globally compromised ability to regulate the unfolded protein response and it has been widely used for studying ER stress process [17-19]. With the plate array assay, the activities of 48 TFs can be elucidated in a single experiment. Through a comparative study, it was observed that the activities of ATF4 and ATF6, XBP1, CHOP, AP1, NFkB, NFAT, TCF/ LEF and HIF increased, while the activity of PXR decreased to different extents in response to TM and TG treatment. To our knowledge, the activation of NFAT, TCF/LEF, HIF and PXR under ER stress was observed for the first time. The altered TFs were further confirmed by conventional gel shift assays and luciferase reporter assays. Different patterns of TF activities in $\mathrm{MiaPaCa} 2$ were exhibited in response to different TM or TG treatment time, which may help to unveil the complicated mechanism of ER stress process.

\section{Methods}

\section{Cell culture and nuclear extraction}

MiaPaCa2 cells were seeded in $10 \mathrm{~cm}^{2}$ culture plates in ATCC-formulated Dulbecco's Modified Eagle's Medium (ATCC), supplemented with $10 \%$ FBS, $1 \%$ nonessential minimal amino acids and $100 \mathrm{U} / \mathrm{ml}$ penicillin, $0.1 \mathrm{mg} / \mathrm{ml}$ streptomycin. The cells (about $80 \%$ confluent) were then treated with 200nM TG and 10ug/ml TM for $1 \mathrm{~h}, 4 \mathrm{~h}, 8 \mathrm{~h}$ and $16 \mathrm{~h}$ respectively. Untreated cells were used as negative controls. Nuclear extracts were prepared with the nuclear extract kit (Signosis, Inc.) according to the user manual. The cells were washed twice in phosphatebuffered saline (PBS) and lysed on ice for $10 \mathrm{~min}$ in the extraction buffer I with gently shaking, and then were collected from the plates, and centrifuged at $15,000 \mathrm{rpm}$ for $3 \mathrm{~min}$ at $4{ }^{\circ} \mathrm{C}$. The supernatant (cytoplasmic fraction) was discarded; the pellet was then resuspended in $250 \mu \mathrm{l}$ of extraction buffer II and incubated on ice for $2 \mathrm{~h}$ with gently shaking. After the mixture was centrifuged at $15,000 \mathrm{rpm}$ for $5 \mathrm{~min}$ at $4{ }^{\circ} \mathrm{C}$, the supernatant containing nuclear protein was collected and ready for assays. Protein concentrations were determined by the Bradford assay (Bio-Rad). 


\section{TF activation profiling analysis}

Each array assay was performed following the procedure described in the TF activation profiling plate array kit user manual (Signosis, Inc). 10 ug of nuclear extract was first incubated with the biotin labeled probe mix at room temperature for $30 \mathrm{~min}$. The activated TFs were bound to the corresponding DNA binding probes. After the protein/ DNA complexes were isolated from unbound probes, the bound probes were eluted and hybridized with the plate pre-coated with the capture oligos. The captured biotinlabeled probes were then detected with Streptavidin-HRP and subsequently measured with the chemiluminescent plate reader (Veritas microplate luminometer).

\section{Gel shift assay}

The samples with $8 \mathrm{~h}$ of TG and TM treatment were chosen for gel shift assay analysis with EMSA kits (Signosis Inc). The TF DNA binding probe sequences are listed below.

1) ATF: CTGTCATGACGTCAAAAGTCG

2) NFkB: AGTTGAGGGGACTTTCCCAGGC

3) NFAT: ACGCCCAAAGAGGAAAATTTGTTTCATACA

4) AP1: CGCTTGATGACTCAGCCGGAA

5) CHOP: TTGCGGAGGATTGCGTTGACGA

6) TCF/LEF: ACGTTACTTTGATCTGATCAGGGC

7) XBP1:

\section{GATCTCCTAGCAACAGATGCGTCATCTC} 8) HIF: GTGACTACGTGCTGCCTAG

The sequences that we used as probes for gel shift assay are identical to those we used as the probe mix for TF activation profiling array assay. 5ug nuclear extracts were incubated with $1 \times$ binding buffer and biotinlabeled probe for $30 \mathrm{~min}$ at room temperature to form protein/DNA complexes. The samples were then electrophoresed on a $6 \%$ polyacrylamide gel in $0.5 \% \mathrm{TBE}$ at $120 \mathrm{~V}$ for $45 \mathrm{~min}$ and then transferred onto a nylon membrane in $0.5 \% \mathrm{TBE}$ at $300 \mathrm{~mA}$ for $1 \mathrm{~h}$. After transfer and UV cross-linking, the membrane was detected with Streptavidin-HRP. The image was acquired using a FluorChem imager (Alpha Innotech Corp).

\section{Luciferase reporter assay}

Luciferase reporter assay was carried out following the procedure in Luciferase reporter assay user manual (Signosis, Inc.). The reporter vectors contain 4 repeats of the corresponding DNA binding sequences shown in gel shift assay section. In order to distinguish ATF4 and ATF6 activation, we cloned the reporter vectors for ATF4 and ATF6 with 5 repeats of specific consensus sequences for ATF4 and ATF6 respectively, TGACGTAAG [20] for ATF4 and TGACGTGG [21] for ATF6. The cells were first transfected with luciferase reporter vectors (Signosis Inc) for $16 \mathrm{~h}$ with Fugene 6 (Promega) in a 96well plate, and then treated without or with $200 \mathrm{nM}$ TG and $10 \mathrm{ug} / \mathrm{ml}$ TM for $6 \mathrm{~h}, 8 \mathrm{~h}$ and $16 \mathrm{~h}$ respectively. After removing the culture media and rinsing the cells twice with PBS, $200 \mu \mathrm{l}$ of $1 \times$ cell lysis buffer was added to lyse the cells. After dislodging the cells by scraping them off from the plate, we transferred the cells to a 1.5$\mathrm{ml}$ microcentrifuge tube before being centrifuged at $14,000 \mathrm{rpm}$ at room temperature for $1 \mathrm{~min}$ to remove cellular debris. $10 \mu \mathrm{l}$ of the cell extract was mixed with $50 \mu \mathrm{l}$ of substrate (Signosis Inc), and luminescence was measured using a luminometer.

\section{Statistical analyses}

Data were analyzed by a method of two-sided and unpaired $t$-test using GraphPad Prism 6.0 software. The mean \pm SD of multiple independent experiments were shown in data analysis. A $p$ value of $<0.05^{*}$ would be considered significant, $p<0.01^{* *}$ very significant, and $p<0.001^{* * * *}$ highly significant.

\section{Results and discussion}

To examine TF activation patterns induced by ER stress, MiaPAC2 cells were treated with or without TG or TM for $1 \mathrm{~h}, 4 \mathrm{~h}, 8 \mathrm{~h}$ and $16 \mathrm{~h}$ prior to preparation of nuclear extracts for analysis with the TF activation profiling plate array I with slight modification (Table 1). The TFs were selected based on their important biological functions in crucial signal pathways which may associate with ER stress. The nuclear extracts were mixed with a biotinlabeled pool of DNA probe mix that correspond specifically to $48 \mathrm{TF}$ response elements. After the probes were incubated with nuclear extracts, the complexes of TFs and probes were separated from the free probes. Through elution of bound probes, the composition and quantity of the bound probes were then determined using a plate array, which contained the pre-coated capture oligos in a 96well white plate according to the position of the individual TFs indicated in Table 1, therefore, the plate would hybridize with any labeled probe that was present. After the hybridized signals were detected with a StreptavidinHRP and HRP substrate, the resulting chemiluminescence was measured by a plate reader. The evolution of TF activity pattern in response to ER stress process was examined in a chronological sequence. The ATF and XBP1 activities were shown to increase significantly after only $1 \mathrm{~h}$ of TG and TM treatment. The activities of CHOP, AP1, NFkB, NFAT, TCF/LEF and HIF showed significant increases after $4 \mathrm{~h}$ of TG and TM treatment. All of TF activities reached to peak upon $8 \mathrm{~h}$ of TG and TM treatment. After $16 \mathrm{~h}$ treatment, only NFAT and TCF/LEF activities remained the same level as $8 \mathrm{~h}$ treatment, and the other TFs all decreased slightly (Fig. 1). In addition, we identified that the activity of 
Table 1 The diagram of TF Activation Plate Array I (revised). 48 TFs are included, locating in the column 1-6 and column 7-12 respectively

\begin{tabular}{|c|c|c|c|c|c|c|c|c|c|c|c|c|}
\hline & 1 & 2 & 3 & 4 & 5 & 6 & 7 & 8 & 9 & 10 & 11 & 12 \\
\hline A & AP1 & CDP & GATA & XBP & Pit & Stat3 & AP1 & CDP & GATA & XBP & Pit & Stat3 \\
\hline B & AP2 & CREB & GR/PR & NFAT & PPAR & Stat4 & AP2 & CREB & GR/PR & NFAT & PPAR & Stat4 \\
\hline C & AR & E2F-1 & $\mathrm{HIF}$ & $\mathrm{CHOP}$ & PXR & Stat5 & AR & E2F-1 & HIF & $\mathrm{CHOP}$ & PXR & Stat5 \\
\hline D & ATF & EGR & HNF4 & NFkB & SMAD & Stat6 & ATF & EGR & HNF4 & NFkB & SMAD & Stat6 \\
\hline E & Brn-3 & ER & IRF & Oct-4 & Sp1 & TCF/LEF & $\mathrm{Bm}-3$ & ER & IRF & Oct-4 & Sp1 & TCF/LEF \\
\hline$F$ & CIEBP & Ets & MEF4 & p53 & SRF & TR & CIEBP & Ets & MEF2 & p53 & SRF & $\mathrm{TR}$ \\
\hline G & CAR & FAST-1 & Myb & Pax-5 & SATB1 & YY1 & CAR & FAST-1 & Myb & Pax-5 & SATB1 & YY1 \\
\hline $\mathrm{H}$ & CBF & GAS/ISRE & Myc-Max & $\mathrm{Pbx} 1$ & Stat1 & TFIID & CBF & GAS/ISRE & Myc-Max & $\mathrm{Pbx} 1$ & Stat1 & TFIID \\
\hline
\end{tabular}

PXR decreased significantly after $4 \mathrm{~h}$ of TG treatment but only slightly decreased in TM-treated cells. Furthermore, HIF, TCF/LEF, NFAT and PXR were observed to be ER stress responsive TFs for the first time.

In order to validate the plate array results, the samples with optimal $8 \mathrm{~h}$ of TG and TM treatment were used for gel shift assay. As shown in Fig. 2, both TG- and TM- activated ATF, XBP1, CHOP, AP1, NFkB, NFAT and HIF were able to be confirmed with gel shift assays. The decrease of PXR in DNA binding activity in TG-treated cells was also confirmed with the gel shift assay but the slight change in the activity of PXR in TM-treated cells identified by the plate array was not detectable with the gel shift assay. As the gel shift assay is considered to be
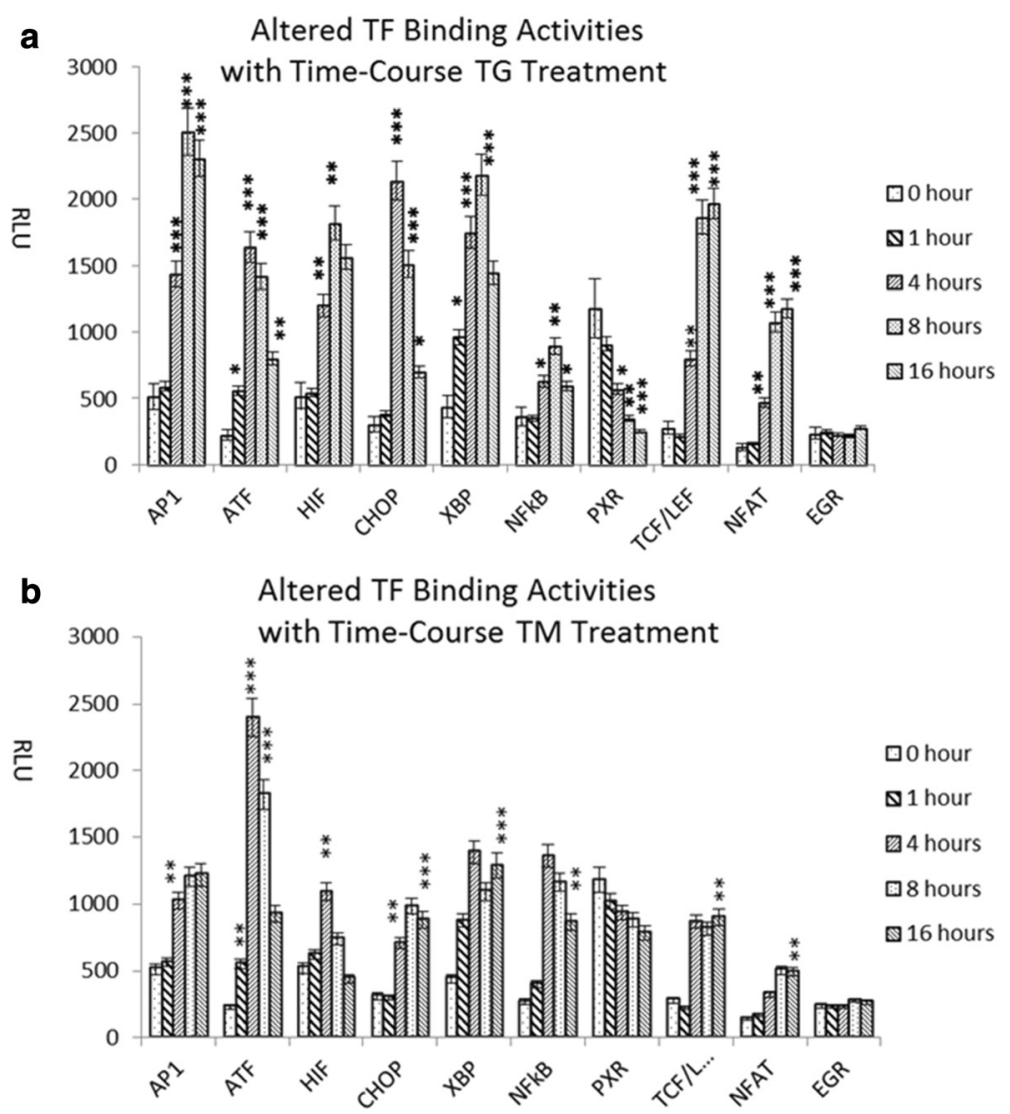

Fig. 1 Plate array analysis of 48 TFs in MiaPAC2 cells treated without or with TG/TM treatment respectively. After $1 \mathrm{~h}, 4 \mathrm{~h}, 8 \mathrm{~h}$ and $16 \mathrm{~h}$ of treatment, the cells were subjected to nuclear extraction. The nuclear extracts were then used for TF activation plate assay. The data from control sample (without treatment), TG treated and TM treated samples were compared. Data were obtained from three independent experiments, ${ }^{*} P<$ $0.05,{ }^{* *} P<0.01,{ }^{* *} P<0.001$; (a): TF activation DNA binding assay with TG treatment; (b). TF activation DNA binding assay with TM treatment 


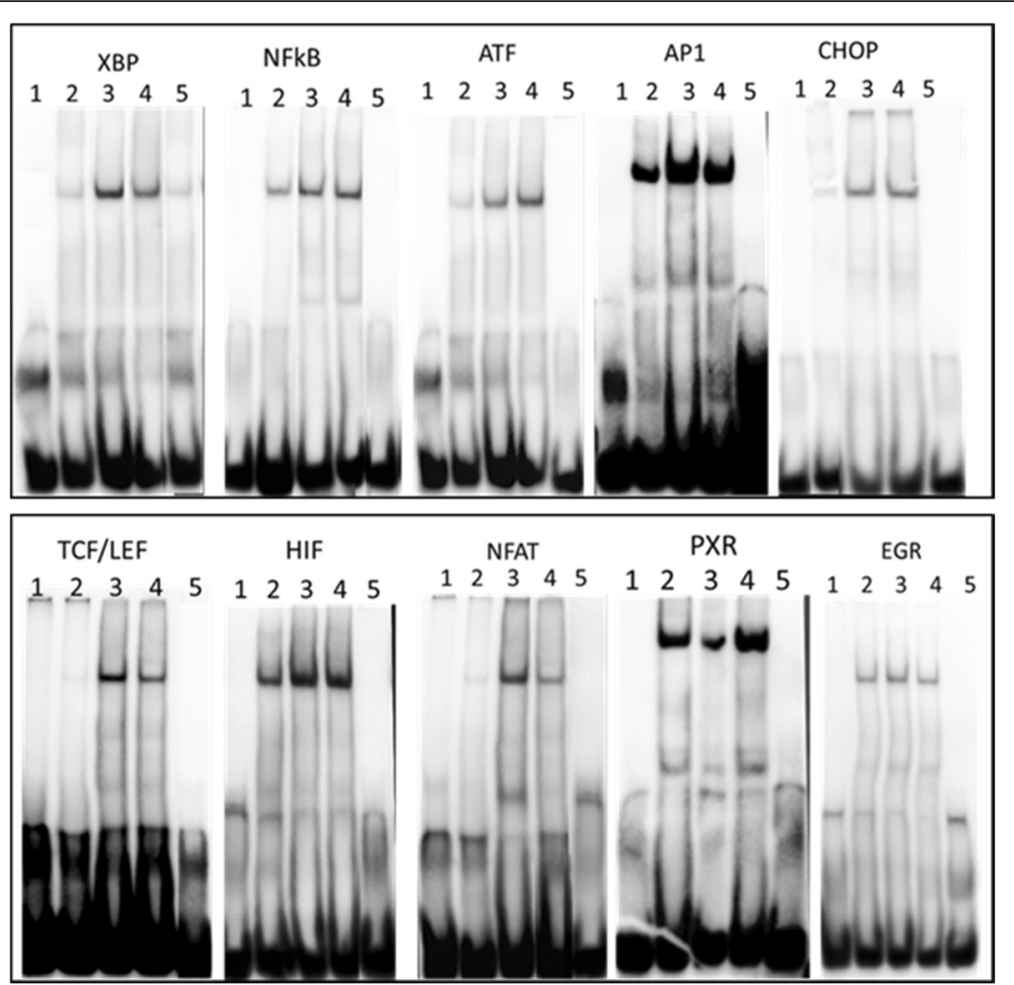

Fig. 2 Nuclear extracts with $8 \mathrm{~h}$ of treatment were subjected to EMSA assay with different probes. a: TFs, XBP, NFkB, ATF, AP1 and CHOP, were reported to be associated with ER stress previously. b: TFs, TCF/LEF, HIF, NFAT and PXR, were the first time reported to be associated with ER stress in this study. EGR was used as a negative control. 1. Free probe only. 2. Without treatment; 3. TG treatment; 4. TM treatment; 5. Cold probe competition

a gold standard in analysis of DNA binding activities of TFs, we concluded that the activities of PXR decreased in TG-treated but not TM-treated cells. Furthermore, we introduced EGR as a control in gel shift assay. The array data showed no change of ERG in either TG- or TMtreated cells as compared to the untreated MiaPAC2 cells. The gel shift assay showed no difference in EGR between treated and untreated cells (data not shown). Through both the array and gel shift assays, we confirmed that ATF, XBP1, CHOP, AP1, NFkB, TCF/LEF, NFAT and HIF are indeed activated by TG and TM. The activity of PXR was down regulated by TG but not by TM.

In order to investigate whether the activation of these TFs can be quantitatively monitored with luciferase reporter assays, we employed a set of reporter vectors corresponding to these TFs to transfect into MiaPAC2 cells. The consensus sequence of ATF probe in the TF activation plate array assay and gel shift assay are for ATF family but cannot distinguish ATF family members, ATF4 and ATF6. We designed and cloned ATF4 and ATF6 reporter vectors with specific ATF4 and ATF6 DNA binding sequences respectively. After transfection of the vectors into the cells, the cells were treated with TG and TM treatment for $6 \mathrm{~h}, 8 \mathrm{~h}$ and $16 \mathrm{~h}$ before their luciferase activity was measured. We confirmed the activation of ATF4, ATF6, XBP1, CHOP, AP1, NFkB, TCF/LEF, NFAT and HIF by TG and TM treatment, and repression of PXR by TG only but not by TM. The activation of ATF4 and XBP1 was observed to occur at the earlier stage during ER stress process. In addition, TG was shown to be a stronger inducer for CHOP, XBP, AP1, TCF/LEF, and PXR, whereas TM-activated ATF4, ATF6 and NFkB were shown to much more effective than TG. HIF responded equivalently to both TM and TG treatments (Fig. 3).

A possible mechanism underlying alteration of newly identified NFAT, HIF, TCF/LEF and PXR activities during ER stress process is presented here for further discussion. TM blocks the initial step of glycoprotein biosynthesis in the ER. Thus, treatment of TM causes accumulation of unfolded glycoproteins in the ER, effectively triggers eIF2 $\alpha /$ ATF4 pathway and activates ATF4. ATF4 has demonstrated to be an early activated TF during early ER stress process and is the master regulator that plays a crucial role in the adaptation to stresses by regulating the transcription of many genes, such as CHOP and ATF6. These ATF4 target genes are themselves transcription factors that regulate the expression of a set of stress-induced target genes and amplify the signals by triggering other signaling pathways, such 


\section{a \\ Reporter Assay Analysis of TF Transactivations in Response to TG Treatment}

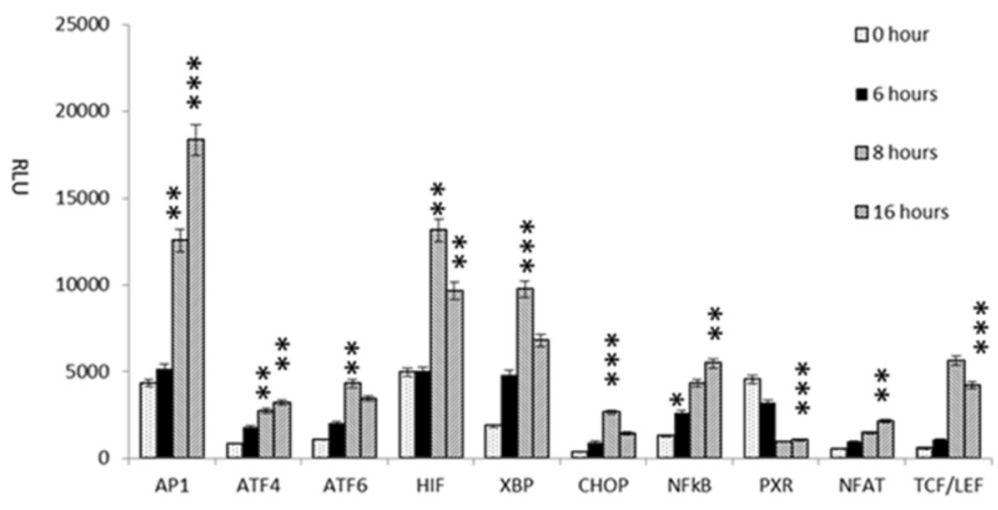

b Reporter Assay Analysis of TF Transactivations in Response to TM Treatment

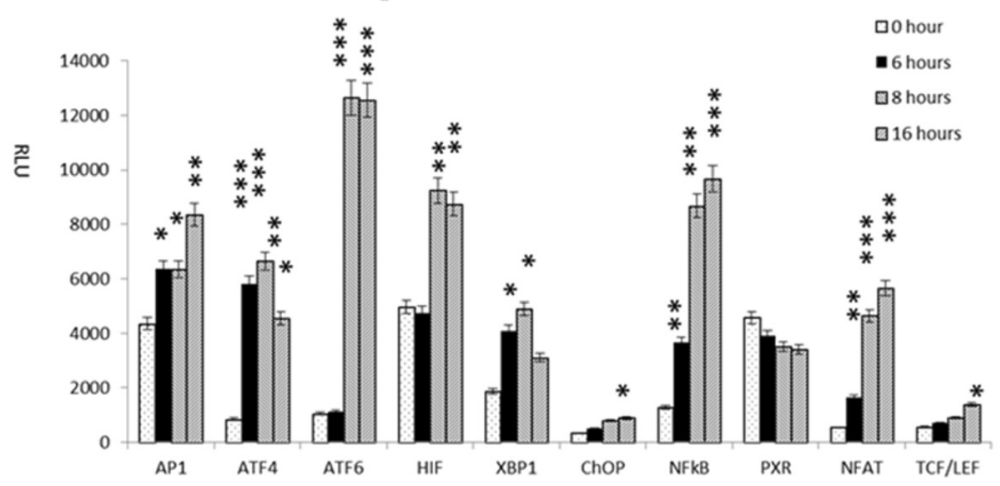

Fig. 3 Transactivation of TFs in response to TG and TM treatment. The cells were transfected with different reporter vectors for $16 \mathrm{~h}$, and treated with TG or TM respectively for $0 \mathrm{~h}$ (no treatment), $6 \mathrm{~h}, 8 \mathrm{~h}$ and $16 \mathrm{~h}$ The cells then were lysed and subjected to luciferase assay. Data were obtained from three independent experiments, ${ }^{*} P<0.05,{ }^{* *} P<0.01,{ }^{* * *} P<0.001$; (a): Reporter assay with TG treatment; (b): Reporter assay with TM treatment

as inflammation and hypoxia via activating $\mathrm{NFkB}$ and HIF. Activation of these multiple TFs by the ER (UPR) may result in a complicated pattern of gene regulation through not only by target gene regulation but also by protein/protein interaction. It agrees with the observation from one of our previous studies that, the altered activities of TFs can be induced either by over expression TF or by interaction of TF with other proteins [22]. In addition, TG that can generate Cadysregulation and induce ER stress may result in significant increases in cytosolic $\mathrm{Ca}^{2} . \mathrm{Ca}^{2}$ disequilibrium releases beta-catenin from the plasma membrane, which subsequently leads to the accumulation of beta-catenin in the cytoplasm and formation of beta-catenin/TCF/LEF complex. This complex further translocates to the nucleus where it activates transcription [23]. Increased $\mathrm{Ca}^{2}$ concentration in the cytoplasm could also directly activate NFAT. ER stress has been reported to lead to the phosphorylation of HIF- $1 \alpha$, which might result in an increase in the activity of HIF-1 $\alpha[24,25]$. PXR is a nuclear receptor recognized as a major regulator of xenobiotic metabolism and drug metabolism by regulating CYP3A4 [26]. The expression of PXR has been reported to be suppressed during ER stress by down-regulating HNF4 and up-regulating liver-enriched inhibitory protein (LIP) with TG treatment. The decrease in DNA binding activity of TG-induced PXR discovered in this study may be due to the pathway interactions with HNF4, ATF and CHOP [27]. With the array assay the different TF activity patterns were displayed in response to different ER stress pathways. Formation of homo- and heterodimers among these TFs families may build an integrated transcription factor network that determines precisely the initiation, magnitude, and length of the cellular response to ER stress in a fine-tuned and coordinated way. In spite of the exact mechanism how ER stress is regulated by TFs still remains not fully clear, the new findings in this study offer clues to dissect the cellular response to ER stress signaling pathways. 


\section{Conclusion}

We used TF activation plate array to profile the TF activities of TFs and reported four newly identified TFs whose activities were altered in response to ER stress. The activity patterns were shown to be distinctive with the different ER signal pathways.

\section{Abbreviations}

AP1: activating protein; ATF: activating transcription factor; CHOP: DNA damage inducible transcript 3; ER: endoplasmic reticulum; HIF: hypoxia inducible factor; NFkB: nuclear factor of kappa light polypeptide gene enhancer in B-cells; PXR: pregnane X receptor; TCF/LEF: T-cell factor/ lymphoid enhancer factor; TF: transcription factor; TG: thapsigargin; TM: tunicamycin; UPR: unfolded protein response; XBP: X-box binding protein

\section{Competing interests}

The authors declare that Sheena Jiang and Xianqiang Li are employed by Signosis Inc, and may gain financially from the company in future. Eric Zhang and Rachel Zhang don't gain financially from the company in the future.

\section{Authors' contributions}

SJ and XL came up with the idea and wrote the manuscript. SJ conducted the tissue culture and luciferase reporter assay. SJ and EZ performed nuclear extraction and TF activation plate array. EZ and RZ performed EMSA. RZ edited the paper. All authors read and approved the final manuscript.

\section{Acknowledgements}

This work is supported by Signosis Inc.

\section{Author details}

${ }^{1}$ Signosis Inc., 1700 Wyatt Drive, Suite \#10-12, Santa Clara, CA 95054, USA

${ }^{2}$ Saratoga High School, 20300 Herriman Ave, Saratoga, CA 95070, USA.

Received: 10 August 2015 Accepted: 2 March 2016

Published online: 24 March 2016

\section{References}

1. Gething MJ, Sambrook J. Protein folding in the cell. Nature. 1992;355:33-45.

2. Xu C, Bailly-Maitre B, Reed JC. Endoplasmic reticulum stress: cell life and death decisions. J Clin Invest. 2005:115:2656-64.

3. Sidrauski C, Chapman R, Walter P. The unfolded protein response: an intracellular signalling pathway with many surprising features. Trends Cell Biol. 1998;8:245-9.

4. Mori K. Tripartite management of unfolded proteins in the endoplasmic reticulum. Cell. 2000;101:451-4.

5. Zhang K. Integration of ER stress, oxidative stress and the inflammatory response in health and disease. Int J Clin Exp Med. 2010;3(1):33-40.

6. DuRose JB, Tam AB, Niwa M. Intrinsic capacities of molecular sensors of the unfolded protein response to sense alternate forms of endoplasmic reticulum stress. Mol Biol Cell. 2006;17:3095-310.

7. Lipson KL, Fonseca SG, Ishigaki S, Nguyen LX, Foss E, Bortell R, Rossini AA, Urano F. Regulation of insulin biosynthesis in pancreatic beta cells by an endoplasmic reticulum-resident protein kinase IRE1. Cell Metab. 2006;4:245-54

8. Wu J, Kaufman RJ. From acute ER stress to physiological roles of the unfolded protein response. Cell Death Differ. 2006:13:374-84.

9. Teske BF, Wek SA, Bunpo P, Cundiff JK, McClintick JN, Anthony TG, Wek RC. The elF2 kinase PERK and the integrated stress response facilitate activation of ATF6 during endoplasmic reticulum stress. Mol Biol Cell. 2011;22(22): 4390-405.

10. Harding HP, Novoa I, Zhang Y, Zeng H, Wek R, Schapira M, Ron D. Regulated translation initiation controls stress-induced gene expression in mammalian cells. Mol Cell. 2000;6:1099-108.

11. Ron D, Walter P. Signal integration in the endoplasmic reticulum unfolded protein response. Nat Rev Mol Cell Biol. 2007:8:519-29.

12. Yoshida H, Matsui T, Yamamotot A, Okada T, Mori K. XPB1 mRNA is induced by ATF6 and spliced by IRE 1 in response to ER stress to produce a highly active transcription factor. Cell. 2001;107:881-91.
13. Yamamoto K, Yoshida H, Kokame K, Kaufman RJ, Mori K. Differential contributions of ATF6 and XBP1 to the activation of endoplasmic reticulum stress-responsive cis-acting elements ERSE, UPRE and ERSE-II. J Biochem. 2004;136:343-50.

14. Hummasti S, Hotamisligil GS. Endoplasmic reticulum stress and inflammation in obesity and diabetes. Circ Res. 2010;107:579-91.

15. Ozcan L, Tabas I. Role of endoplasmic reticulum stress in metabolic disease and other disorders. Annu Rev Med. 2012;63:317-28.

16. Oslowski CM, Urano F. Measuring ER stress and the unfolded protein response using mammalian tissue culture system. Methods Enzymol. 2011:490:71-92

17. Verma G, Datta M. IL-1 beta induces ER stress in a JNK dependent manner that determines cell death in human pancreatic epithelial MIA PaCa-2 cells. Apoptosis. 2010;15(7):864-76.

18. Cheng S, Swanson K, Eliaz I, McClintick JN, Sandusky GE, Sliva D. Pachymic acid inhibits growth and induces apoptosis of pancreatic cancer in vitro and in vivo by targeting ER stress. PLoS One. 2015;10(4), e0122270.

19. Cheng S, Swanson K, Eliaz I, McClintick JN, Sandusky GE, Sliva D. Imexon induces an oxidative endoplasmic reticulum stress response in pancreatic cancer cells. Mol Cancer Res. 2012;10(3):392-400.

20. Bouman L, Schlierf A, Lutz AK, Shan J, Deinlein A, Kast J, Galehdar Z, Palmisano V, Patenge N, Berg D, Gasser T, Augustin R, Trümbach D, Irrcher I, Park DS, Wurst W, Kilberg MS, Tatzelt J, Winklhofer KF. Parkin is transcriptionally regulated by ATF4: evidence for an interconnection between mitochondrial stress and ER stress. Cell Death Differ. 2011; 18(5):769-82.

21. Wang Y, Shen J, Arenzana N, Tirasophon W, Kaufman RJ, Prywes R. Activation of ATF6 and an ATF6 DNA binding site by the endoplasmic reticulum stress response. J Biol Chem. 2000;275:27013-20.

22. Jiang X, Norman M, Roth L, Li X. Protein-DNA array-based identification of transcription factor activities regulated by interaction with the glucocorticoid receptor. J Biol Chem. 2014;279:38480-5.

23. Carlisle RE, Heffernan A, Brimble E, Liu L, Jerome D, Collins CA, MohammedAli Z, Margetts PJ, Austin RC, Dickhou JG. TDAG51 mediates epithelial-tomesenchymal transition in human proximal tubular epithelium. Am J Physiol Renal Physiol. 2012;303:F467-81.

24. Pereira ER, Frudd K, Awad W, Hendershot LM. Endoplasmic reticulum (ER) stress and hypoxia response pathways interact to potentiate hypoxiainducible factor 1 (HIF-1) transcriptional activity on targets like vascular endothelial growth factor (VEGF). J Biol Chem. 2014;289:3352-64.

25. Werno C, Zhou J, Brune B. A23187, ionomycin and thapsigargin upregulate mRNA of HIF-1alpha via endoplasmic reticulum stress rather than a rise in intracellular calcium. J Cell Physiol. 2008;215:708-14.

26. Vachirayonsti T, Ho KW, Yang D, Yan B. Suppression of the pregnane $X$ receptor during endoplasmic reticulum stress is achieved by downregulating hepatocyte nuclear factor-4a and up-regulating liver-enriched inhibitory protein. Toxicol Sci. 2015;144:382-92.

27. Desvergne $B$, Michalik $L$, Wahli $W$. Transcriptional regulation of metabolism. Physiol Rev. 2006;86:465-514.
Submit your next manuscript to BioMed Central and we will help you at every step:

- We accept pre-submission inquiries

- Our selector tool helps you to find the most relevant journal

- We provide round the clock customer support

- Convenient online submission

- Thorough peer review

- Inclusion in PubMed and all major indexing services

- Maximum visibility for your research

Submit your manuscript at www.biomedcentral.com/submit
Biomed Central 